\title{
La arqueología y el mito de origen de los shipibo-conibo de la Amazonía peruana
}

\author{
Daniel Morales Chocano \\ Universidad Nacional Mayor de San Marcos \\ dmoralesc1@unmsm.edu.pe \\ Ana Mujica Baquerizo \\ Universidad Nacional Mayor de San Marcos \\ ana.mujica@unmsm.edu.pe
}

\begin{abstract}
RESUMEN
El artículo contrasta la evidencia etnográfica sobre el mito de origen de los Shipibo-Conibo con la cultura material arqueológica de la cuenca del río Ucayali en la Amazonía peruana, llegando a la conclusión que el mito de origen etnográfico se correlaciona con las etapas de desarrollo cultural de sus ancestros arqueológicos.
\end{abstract}

Palabras clave: mito; arqueología; origen; shipibo-conibo; lengua pano; estilo Pacacocha; cumancaya; policromo.

\section{The archeology and origin myth of the Shipibo-Conibo from Peruvian Amazon}

\begin{abstract}
The article confirms the ethnographic evidence on the myth of origin of the Shiibo-Conibo with the material archaeological culture of the basin of the Ucayali in the Peruvian Amazonía, coming to interesting conclusions.
\end{abstract}

KeYwords: Myth; archeology; origin; Shipibo-Conibo; Pano language; Pacacocha style; Cumancaya; polychrome. 


\section{Introducción}

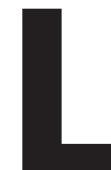

os Shipibo-Conibo pertenecen al grupo lingüístico Panó, actualmente viven en la cuenca del Ucayali Central y Alto Ucayali. Son sociedades rivereñas y el río es muy importante en su vida económica, social e ideología, puede decirse que son culturas del agua, por eso el río es considerado como una gran serpiente a la cual llaman «Ronin", esta serpiente es el centro de su ideología, por ello ha sido denominada la gran serpiente cósmica, en cuyo cuerpo están todos los "Kené» o diseños que los shipibo-conibo pintan en todos sus objetos y artefactos. Los diseńos o "kené» representan el universo celestial en la tierra, tiene al igual que en el cielo, sus ríos o caminos, con sus canoas, también la cruz del sur y la gran constelación de la serpiente o «Ronin» dueña del universo; indudablemente una ideología que nos dice mucho sobre el origen mítico de los pueblos ShipiboConibo, expresado en el Ucayali Central, en la leyenda del antiguo pueblo de Cumancaya, donde se dice que los Shipibo-Conibo emergieron por cuarta vez.

La arqueología de los años de 1970, en base a estudios estilísticos de la cerámica realizados por el arqueólogo Thomas Myers, afirma que los Panó o Shipibo-Conibo llegaron al Ucayali hace 300 años d.C., procedentes del Sur trayendo un estilo de cerámica llamado Pacacocha, mientras que el arqueólogo Donald Lathrap, afirma que los Panó llegaron al Ucayali entre 600 a 800 ańos d. C., cuando un nuevo estilo de cerámica llamado Cumancaya invadió la cuenca del Ucayali, desplazando a las antiguas poblaciones de lengua Arawak. En esta misma línea, Marcel D’Ans (1973) considera que por los estudios de Glotocronología, los panohablantes, o sea, los shipibo-conibo, llegaron al Ucayali hace 100 años d. C.

Nuestras investigaciones arqueológicas en el sitio El Zapotal, entre 2001 y 2003, ubicado en la cuenca del río Samiria, cerca de la confluencia de los ríos Marañón y Ucayali, demuestran en base al estilo de su cerámica que el sitio arqueológico perteneció a los antecesores de los Shipibo-Conibo y Shetebo, lo que indica que este grupo social en el pasado dominaban todo el territorio de la cuenca del Ucayali. En este lugar entre los años 1350 a $1450 \mathrm{~d}$. C. el estilo Cumancaya de los Shipibo-Conibo se fusiona con el Estilo Policromo de la Amazonia Central, dando origen al actual estilo polícromo de los ShipiboConibo, también en este mismo lugar los Panos (Shipibo-Conibo-Shetebo), interactuaron con grandes oleadas de poblaciones de lengua Tupi-Warani entre ellos Omaguas, Cocamas y Cocamillas, que venían de la Amazonía Central y desplazaron a los Shipibo-Conibo de la cuenca baja del Ucayali hasta el Ucayali Central y Alto Ucayali, donde actualmente se encuentran.

En conclusión, en el mito de origen existen cuatro orígenes o emergencias y la arqueología nos indican que la historia de los Shipibo-Conibo se dio hasta en cuatro etapas o generaciones diferenciadas estilísticamente en la cerámica.

\section{¿Quiénes son los shipibo-conibo?}

Los shipibo-conibo y también los Shetebo, pertenecen a un mismo grupo lingüístico llamado Panó, actualmente se ubican en la cuenca alta y media del río Ucayali; son sociedades amazónicas en equilibrio con la naturaleza, viven desde sus antepasados en función de los ríos y lagunas de esta cuenca (Fig. 1, mapa), en este habitat hacen su vida diaria, encuentran su subsistencia, aquí están sus sitios arqueológicos, sus tradiciones, costumbres e ideología, son hoy como ayer las "Culturas del Agua", en donde el rio es comparado a una gran serpiente llamada "Ronin" en lengua Shipibo y "Yacumama» en lengua quechua. Ronin está representada como motivo iconográfico de manera geométrica y estilizada en todos los artefactos pintados como la cerámica, tejidos, macanas y otras herramientas y ornamentos ceremoniales como coronas.

En la ideología, Ronin es la gran serpiente cósmica ( Figs. 2 y 3), que tiene todos los diseños en su piel, esta serpiente mítica creó el universo y simboliza a Dios, dicen que esta serpiente se sostiene fuertemente enroscada en las cuatro esquinas del universo, lista para atacar, al mismo tiempo es emblema de renacimiento e indica el camino hacia una nueva vida que debe seguir el espíritu humano para regresar a la tierra después de la muerte; Ronin que es el río, es también comparado con el cielo, donde las estrellas pasan con sus canoas, dicen que allí hay fuertes corrientes y también existen otros mundos, es decir estos dos mundos, cielo y tierra se replican. 


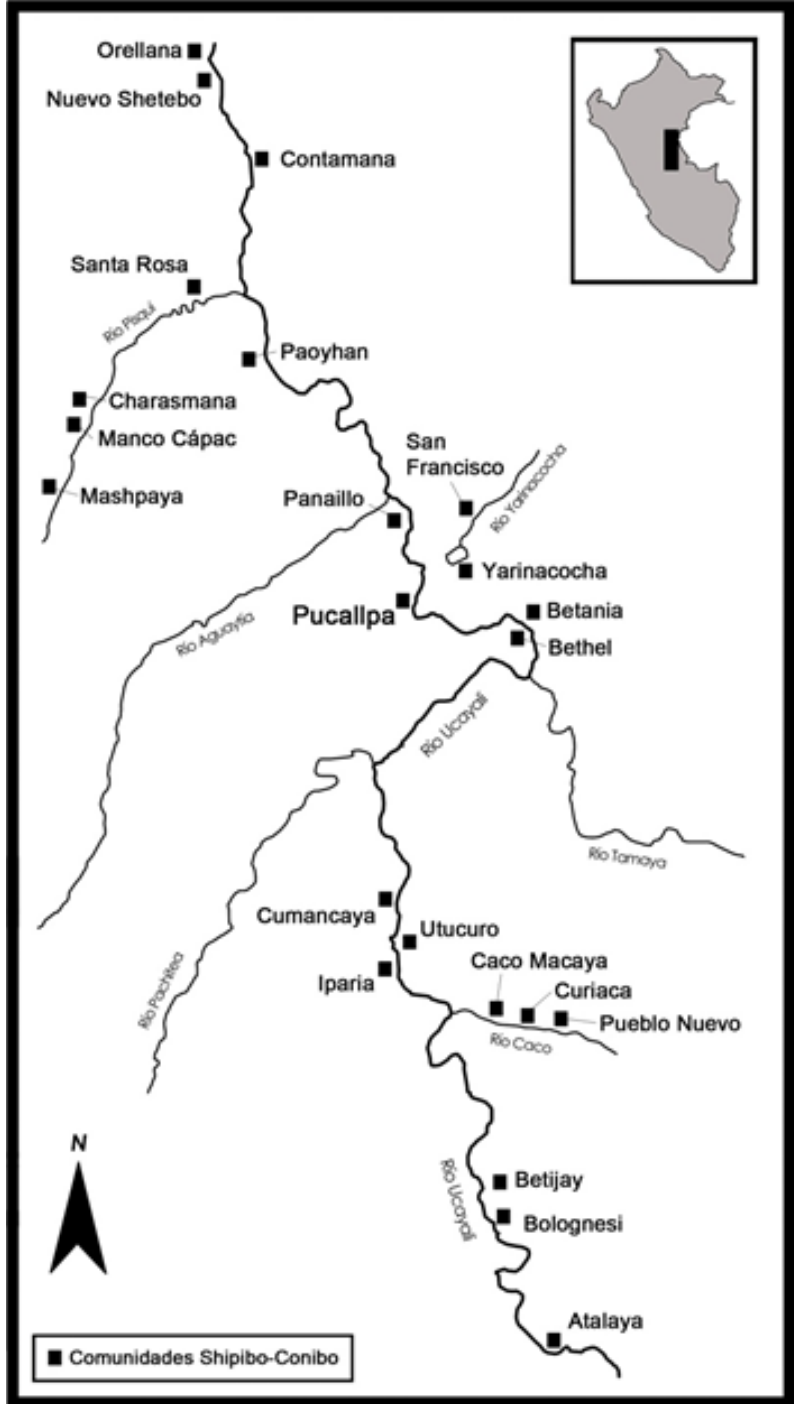

Fig.1. Mapa del territorio actual de los Shipibo-Conibo en la Cuenca del Ucayali.

En la iconografía Shipibo-Conibo, también es frecuente una gran cruz cuadrada, esta misma cruz está en el centro del cielo y no es otra cosa que la Cruz del Sur que domina el cielo durante los meses de sequía, para los Shipibos es la puerta por donde ingresan los muertos al otro mundo (fig. 4). Según L. E. Belaunde (2009), "El ani xeati ya no se lleva a cabo pero su recuerdo perdura y está inscrito en el diseño en cruz (corós kené), y el diseño del espíritu del ojo (vero yoxin) con el que las mujeres adornan actualmente sus chitones y artefactos a la moda actual. El Kene mantiene presente las prácticas del pasado en el día a día y establece la comunicación entre los vivos y los muertos al trazar los caminos que conti-

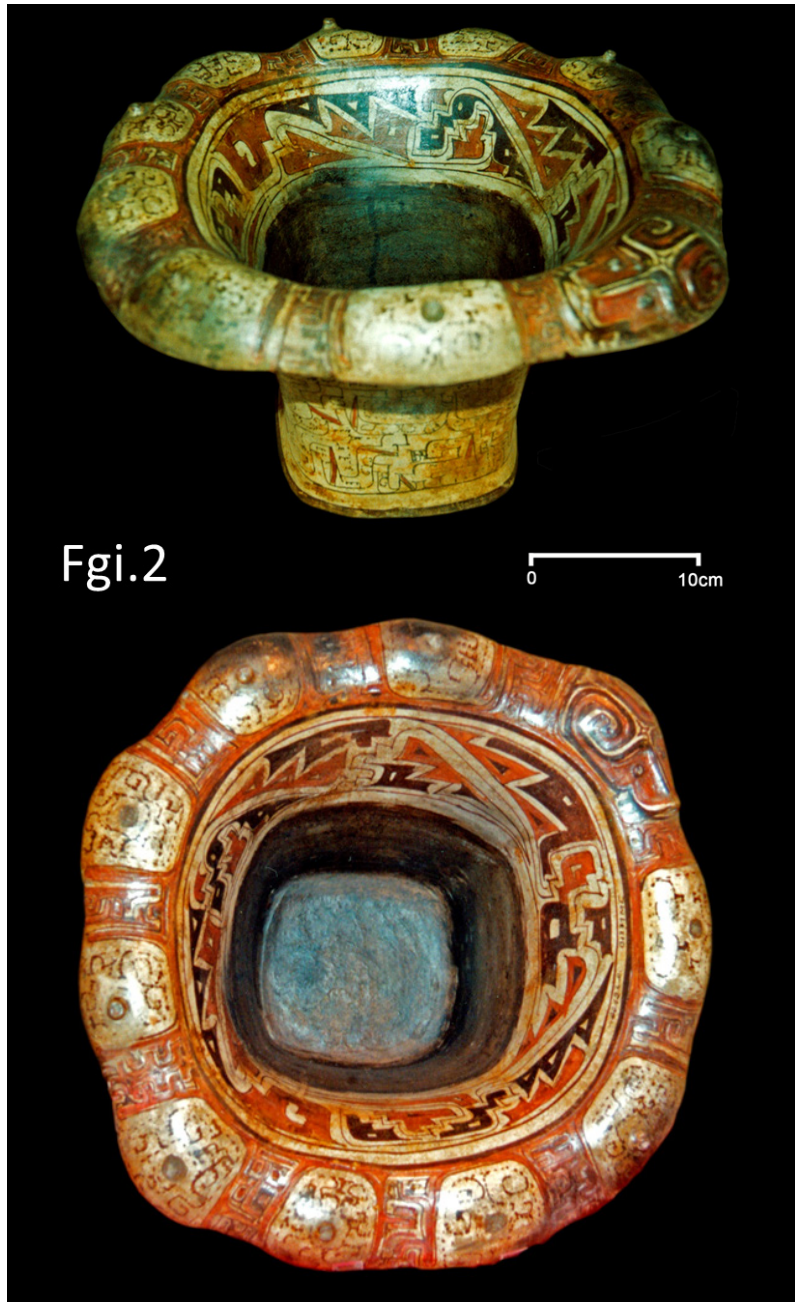

Figs. 2 y 3. Ceramio de estilo Napo (vaso acampanulado),con diseño de la gran serpiente cósmica, llamada «Roni» lleva en su cuerpo todos los diseños o «Keni». Colección del Museo de la Cultura Peruana.

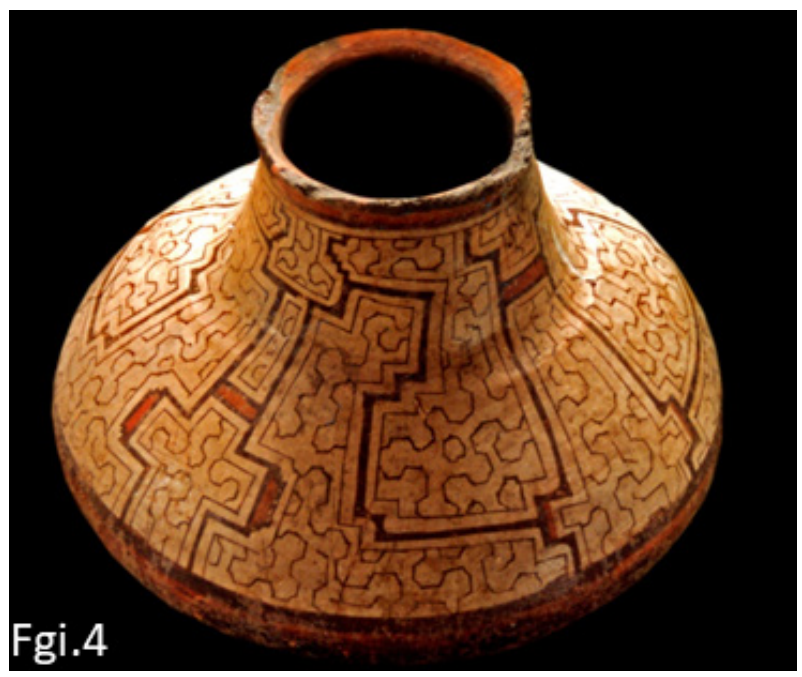

Fig. 4. Cerámica Shipibo-Conibo con motivo de cruz cuadrada o cruz del Sur, por donde ingresan los muertos al otro mundo. 
núan llevando los ancestros a la memoria» (Belaunde 2009: 44).

También el bejuco llamado Ayahuasca o soga del muerto, es identificada con la serpiente cósmica ronin, es madre del Ayahuasca y los ríos, el origen de todos los diseños o kené, se dice también que el Piripiri llamado waste en shipibo también es una manifestación de la anaconda Ronin, ambas plantas Ayahuasca y Piripiri son usadas como alucinógenos para visionar los diseńos o kené, estos representan los caminos de las estrellas de la vía láctea, también los diseños kené en la cerámica o telas para el vestido, representan al cielo o universo, es decir se reproduce el universo o cielo en la tierra, mediante la iconografía de los artefactos.

En la Tierra, los diseños plasmados en los objetos que pertenecen a una persona, no solo tienen un lenguaje cósmico, sino también tienen espíritu y cobran vida, así la ropa como la cushma de los hombres colgada en las paredes del interior de la casa, dicen que es como el mismo dueño que está allí y cuida la casa, tiene espíritu no puede ser tocada, ni usada por otra persona, por eso, el lenguaje simbólico plasmado en los artefactos o vestidos, cobran vida desde el momento que está plasmada o pintada en un objeto, sea este un ceramio, una canoa, la ropa, la macana, la flecha o la casa misma. Haciendo una analogía, esta ideología está plasmada en la iconografía de la Cultura Mochica que se desarrolla en la costa norte del Perú entre 100 a 600 d. C. en las grandes escenas iconográficas pintadas en la cerámica, que es llamada por los arqueólogos «la rebelión de los artefactos», esta ideología alude a los artefactos de guerra o combate ritual que se convierten en seres humanos es decir cobran vida y capturan a los hombres. La segunda analogía de la cultura viva de los Shipibo-Conibo, que encontramos en la iconografía de la cultura Moche, una fue entre la escena Mochica llamada "Combate Ritual» y uno de los ritos de encuentro entre dos personas rivales, que se hacen en la fiesta de Ani-Shati, y que ellos los Shipibo-Conibo llaman "Probando las fuerzas» (Morales 2008)

Indudablemente este pensamiento o ideología cognitiva de los Shipibos-Conibos y también los Shetebos, refleja claramente la gran importancia del medio o habitat en donde ellos nacieron, surgieron y se desarrollaron como las culturas del agua; ésta cosmovisión es suficiente razón para afirmar que los shipibo-conibo y Shetebo tienen un alto desarrollo cognitivo del pensamiento, una gran filosofía y un modo de vida organizada en equilibrio con el cosmos del cielo, la tierra y el agua, elementos de su medio ambiente amazónico, por esto no puede decirse que ellos tienen un origen andino, sino que son absolutamente de origen amazónico. Ellos mismos explican sus orígenes como producto de la dinámica de este gran Río «Ronin» en la cual viven, por ello la vida de estos grupos sociales, también cambia al ritmo del río. En temporadas de crecientes, el río se desborda, inunda los bosques, cambia de curso, arrasa y destruye las poblaciones rivereñas, por esto la economía de supervivencia también decae, porque los peces que son la principal fuente de subsistencia se dispersan en las tierras inundadas del bosque, donde tienen mucha comida y para el hombre es más difícil la pesca, por eso en estas temporadas prefieren cazar en los bosques no inundados donde se concentran los animales; en períodos de vaciante del rio o sequía, ocurre lo contrario, los animales se dispersan por todo el bosque y es más difícil su captura o caza, con la pesca sucede lo contrario, es época de gran abundancia, los peces se concentran en los cauces de los ríos mermados en sus aguas, y migran corriente arriba buscando comida, esta es la temporada de gran actividad en pesca, donde todos los pueblos forman grandes caravanas a orillas o playas de los ríos, donde tratan de acumular la gran cantidad de excedentes del río.

Los pueblos rivereńos que fueron arrasados y desaparecidos por la crecida del río, vuelven a renacer en otra ribera del río, este es un ciclo constante de renacimiento que se explica en el mito de origen de los pueblos Shipibo-Conibo.

\section{El mito de origen}

La leyenda cuenta que los Shipibo-Conibo emergieron en Cumancaya, un sitio arqueológico en el alto Ucayali, para repoblar el mundo por cuarta vez, por eso Cumancayacocha es considerada como el origen de la generación actual de los pueblos ShipiboConibo, también es el centro del universo y es el sitio donde está el árbol cósmico; dice la tradición que en la cocha de Cumancaya existe mucha cerámica rota, 
ellos no la tocan, porque dicen trae mala suerte. Otro sitio ancestral es Canchahuaya en el bajo Ucayali, que al igual que Cumancaya es un sitio arqueológico con mucha cerámica rota, pueblos que probablemente desaparecieron por la furia del río en épocas de creciente y que pertenece a una generación anterior a la actual.

Dice la tradición, que en el pueblo de Cumancaya crecía un árbol encantado, las hojas de este árbol se movían sin viento, y que con el intenso sol sus frutos reventaron y las semillas cayeron al agua de la cocha donde las gamitanas (un pez amazónico muy común) se las comieron y en poco tiempo los peces comenzaron a volar como aves, la gente quedo admirada, decían que seguramente Dios les ha dado esa medicina para volar; entonces tomaron las hojas de aquel árbol, exprimieron su jugo para rociarlo por todo el lindero del pueblo, vamos a volar dijeron, luego la gente se adormeció. Al día siguiente el pueblo amaneció inclinado para empezar a volar y poco a poco el pueblo ascendió en el aire, pero se dice que no se llegó al mundo-cielo y cayeron estrepitosamente y todo la cerámica se rompió en pedazos, por eso es que en esta cocha existe mucha cerámica rota, por ese motivo los Shipibo-Conibo no lo tocan porque esta encantada. ${ }^{1}$

«En síntesis, de acuerdo al mito, el origen de los pueblos Shipibo-Conibo, entendemos que ellos explican de manera dinámica sus orígenes, sujeta a la naturaleza de las crecientes y vaciantes de río, llamado también "Ronin» o serpiente cósmica dueña de universo y que en temporadas de creciente arrasa los pueblos ribereños para luego surgir nuevamente en otras riberas del rio, quedando el sitio arrasado como lugar mítico de origen; por esta razón la última generación de los Shipibo-Conibo tienen sus orígenes en el sitio arqueológico de Cumancaya, donde se dice que emergieron por cuarta vez. De igual manera ellos señalan que el sitio de Canchahuaya en el bajo Ucayali es otro sitio de origen, probablemente de una generación anterior a Cumancaya».

1 Recopilación tomada de Carolyn Heath. En Una ventana hacia el infinito, arte Shipibo-Conibo, 2002. La misma versión también fue recogida por Donald Lathrap (1970).

\section{Lo que dice los arqueologos de los ańos 70}

El arqueólogo Donald Lathrap (1970), interesado por la arqueología amazónica, realizo exploraciones y excavaciones descubriendo más de cien sitios arqueológicos en la cuenca del Ucayali, en base a ello estableció una secuencia cultural de alfareros desde 2,000 a. C., hasta la épocas del contacto con los europeos. Dentro de esta secuencia Lathrap, plantea que los Shipibo-Conibo llegaron al Ucayali, procedentes del Sur, entre 650 a 810 d. C., llevando un nuevo estilo de cerámica que él llama Cumancaya, irrumpiendo en la secuencia anterior de los estilos del Ucayali Central.

Lathrap, asocia este nuevo estilo Cumancaya a los pueblos de lengua Pano, quienes habrían invadido la cuenca desplazando a los antiguos pobladores de lengua Arawak; uno de los argumentos más evidente es que el estilo de la cerámica Shipibo-Conibo deriva según él de la cerámica Cumancaya, por tener ambos muchos rasgos en común, tanto de formas como en decoraciones.

Posteriormente los alumnos de Donald Lathrap, entre ellos Thomas Myers (1970-2002), Roe (1975) y De Boer (1975), difieren en parte con la interpretación de Donald Lathrap, asumiendo que la llegada de la lengua Pano al Ucayali es anterior a la fecha propuesta por Lathrap, para ellos los ShipiboConibo, estaría relacionados a la tradición alfarera Pacacocha, la cual aparece en la secuencia del Ucayali alrededor de 300 d. C., también opinan que el estilo Cumancaya sería resultado de dos componentes distintos: primero, por vasijas simples, cuencos y ollas redondeadas con base plana, a veces con un simple engobe rojo y adornos zoomorfos de la tradición local Pacacocha, y segunda tradición alfarera muy dominante que se caracteriza por el uso de pintura roja entre incisiones, la cual está vinculada a la tradición Sangay del Ecuador; luego a esta tradición después de 2 o 3 siglos se añade la cerámica de estilo corrugada, especialmente en ollas de cocina y también urnas funerarias de cerámica, con temperante de cariapé o corteza de árbol quemada y triturada, la cual es muy común en la zona de Bolivia oriental.

Por estas razones, otro investigador, Brochado en 1984 afirma que el sitio de Cumancaya, sería un pueblo multiétnico, donde los pobladores del estilo de cerámica Rojo entre incisiones eran más numero- 
sa que los de la tradición Pacacocha de lengua Pano. En síntesis los autores mencionados coinciden que Cumancaya sería posterior a la tradición Pacacocha, y ambos están de acuerdo con Donald Lathrap al afirmar que los Shipibo-Conibo tienen una conexión estilística con el estilo Cumancaya, aunque no están seguros de la conexión de los Cumancaya con la lengua Pano.

Hasta aquí, suponemos que los antecedentes de los Shipibo-Conibo en la cuenca del Ucayali se remonta por lo menos a 300 ańos d.C. época en la cual existe en el Ucayali un estilo de cerámica llamado Pacacocha, según T. Myers, estaría vinculado a los Panos hablantes, también hay consenso en pensar que el estilo Cumancaya representaría el apogeo de la tradición Pacacocha.

La presencia de los Panó hablantes (ShipiboConibo), en el Ucayali, también ha tratado de demostrarse a nivel de estudios lingüísticos; Marcel D’Ans (1973), afirma que según la glotocronología o léxico-estadística, los Pano hablantes habrían llegado al Ucayali mucho antes que lo que supone Myers, es decir más o menos 100 años d.C, en este momento el estilo de cerámica en el Ucayali es denominado por Lathrap, como Yarinacocha, se trata de una cerámica burda utilitaria, a veces con engobe rojo y aparecen algunos diseños pintados de rojo, blanco y negro, lamentablemente no se ilustra con dibujos, ni fotos, ni descripción más detallada.

Donald Lathrap, dice que los Yarinacocha fueron desplazados por los Pacacocha, estos permanecieron en la cuenca del Ucayali por más de 400 años y evolucionaron en tres estilos: Pacacocha, Cashibo Caño y Nueva Esperanza; en Pacacocha predominaba las ollas globulares, el engobe rojo, también aparecen soportes macizos de cerámica para poner las ollas en los fogones, así mismo hay grandes vasijas para el masato las cuales también eran utilizadas para entierros secundarios de esqueletos desarticulados. De todos estos rasgos, tanto Yarinacocha, como Pacacocha comparten con la cerámica de los Shipibo-Conibo, el uso de tres colores, blanco, rojo y negro, el engobe rojo y los soportes de vasijas para poner al fogón y lo que es más interesante, comparten las grandes vasijas que también sirven como urnas funerarias para entierros secundarios, si estos rasgos se están asociando a los Pano hablantes, Myers, tiene razón en decir que estos llegaron al Ucayali con el estilo Pacacocha y no con el estilo Cumancaya según lo postulado por Lathrap.

Nosotros pensamos que el actual estilo ShipiboConibo es más complejo, tiene básicamente tres componentes: 1. El estilo de la tradición policromo de la Amazonía Central, similar o parecido al estilo Napo, Miracangeras, Guarita, Marajoara y Caimito, 2. El estilo de cerámica inciso con figuras geométricas con triángulos escalonados que derivan según Myers, de la tradición Sangay del Ecuador de la cerámica de estilo Rojo entre incisiones y el estilo local Pacacocha, a todo ello, Donald Lathrap llama estilo Cumancaya, y 3. El estilo de cerámica utilitaria y corrugada, la cual Según Myers tiene sus orígenes en el Beni Boliviano.

Cuando Donald Lathrap describe el estilo Cumancaya, asociado a los Shipibo Conibo, se refiere a los estilos 2 y 3 , desvinculándola del estilo policromo de Amazonía central e incluso del estilo Caimito del Ucayali el cual está representado en su cuadro secuencial separado del estilo Cumancaya como otra tradición; sin embargo notamos que la cerámica Shipibo-Conibo está más vinculada al estilo policromo de Amazonía central similar o parecida al estilo Napo, Marajoara, Guarita, Miracangeras y Caimito, pues comparten con estas una serie de rasgos, como la policromía de tres colores, los diseños pintados en líneas gruesa y líneas finas y otros rasgos más, como dice Girard (1958), haciendo comparaciones arqueológicas y etnográficas, se descubre que existe una filiación estilística y cultural entre las culturas de Marajó, Napo, Miracangeras y los Shipibo-Conibo. Son comunes entre ellos la cerámica pintada e incisos, la simetría bilateral de sus diseños, los espirales escalonados en rectángulos, la base con pedestal, el barnizado el modelado, los personajes zoomorfos y antropomorfos, las efigies de sexo femenino, figuras cruciformes en forma de $\mathrm{T}$ y $\mathrm{H}$ y el motivo serpiente cósmica estilizada que son expresiones muy frecuentes. También comparten las costumbres de achatarse la frente, tiene dioses antropomorfos femeninos, ritos de pubertad y entierro en ánforas, (Figs. 5, 6 y 7), por todos estos rasgos compartidos, se asume que los pueblos representados por dichas culturas de filiación Pano hablante habrían venido del norte, tal como lo explica una tradición antigua de los Shipibo-Conibo, que dice que se asentaron entre la confluencia del Río Ucayali con el Marañón para luego ser expulsados hasta el Ucayali Central por los Cocamas aliados con los Jebero. 


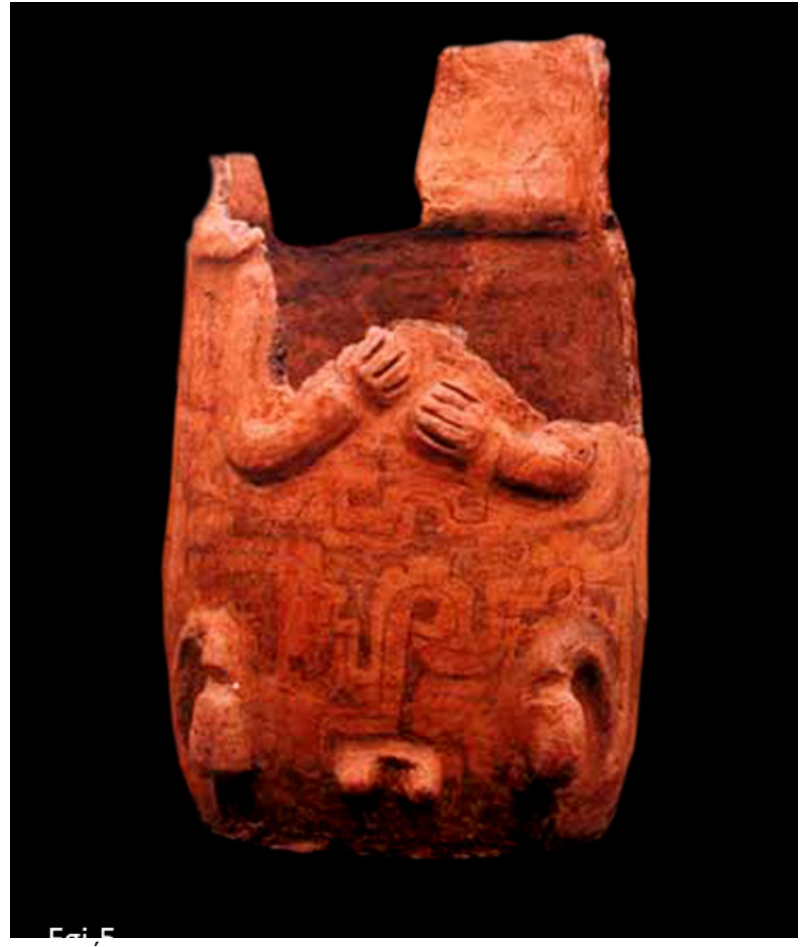

Fig. 5. Ánfora funeraria antropomorfa de entierro secundario de estilo Caymiyo del Ucayali. Colección del MNAH-Perú.

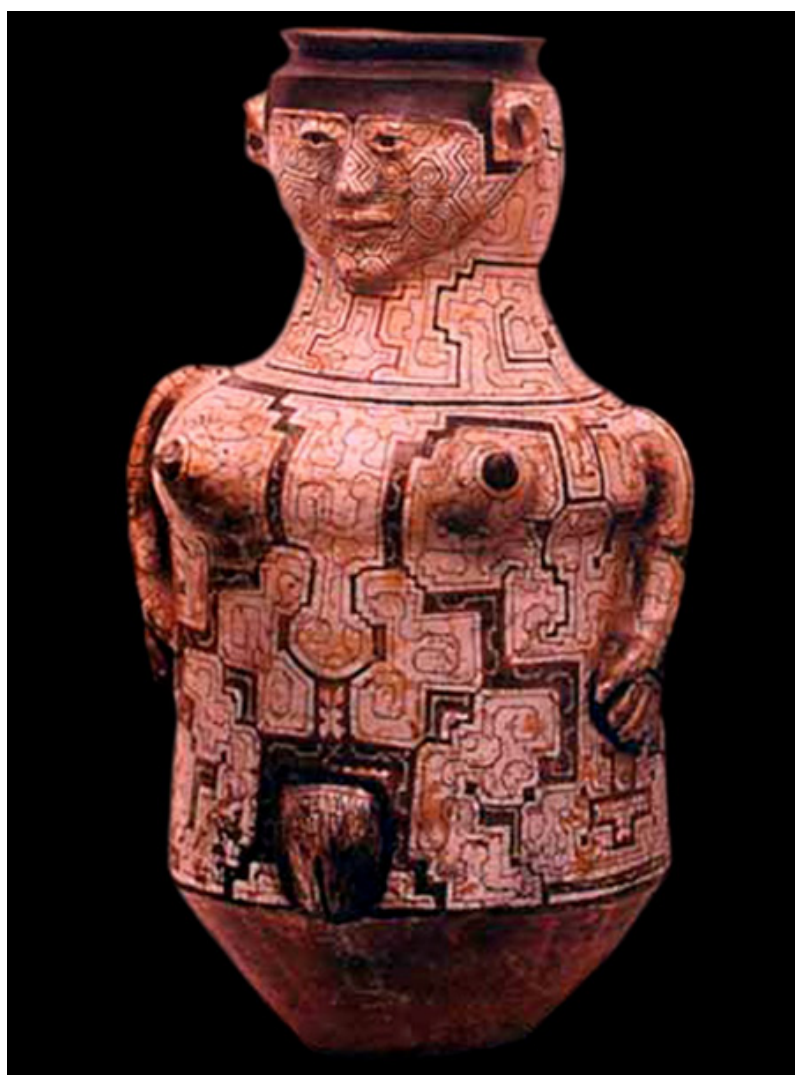

Fig. 7. Ánfora funeraria «Magueta» antropomorfa de estilo policromo de los Shipibo-Conibo.

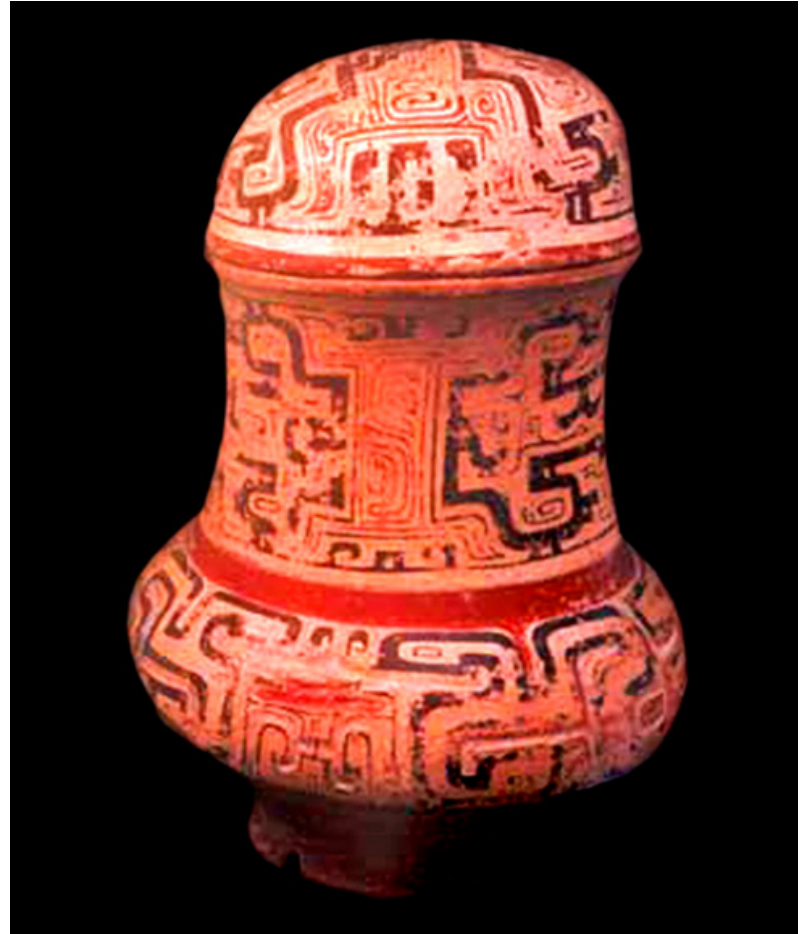

Fig. 6. Ánfora funeraria de estilo policromo de la Cultura Guarita.

\section{Controversias de donde vinieron los shipibo- conibo del norte o del sur}

Según Donald Lathrap, el estilo Cumancaya vinculado a los Shipibo-Conibo, tiene entre sus componentes estilístico la cerámica corrugada en un $20 \%$ y la pintura roja en zonas o el llamado rojo entre incisiones en un $10 \%$ y fechada en un tumba entre 810 d. C. más o menos 80 d. C., según Myers, este estilo de cerámica roja entre incisiones proviene de Sangay en el Ecuador y es el mayor componente en el estilo Cumancaya; Esto indicaría que los Shipibo-Conibo vinieron del Norte, como afirma Girald (1958), al explicar una tradición antigua de los Shipibo-Conibo, sin embargo, Lathrap, Myers y otros que afirmar que los Shipibo-Conibo vinieron del Sur. Lathrap, en particular dice, los motivos incisos de Cumancaya son actualmente hechos por los Mbayá Cadubeos del Mato groso en Brasil y que los antecedentes de estos están alrededor de los $300 \mathrm{~d}$. C antes que la migración de los pueblos Cumancaya, por ello D. Lathrap sugiere que el centro de los proto Pano hablantes se ubica al este de Bolivia y por eso afirma que los Pano (Shipibo-Conibo), vinieron del Sur. Nosotros pensamos que aquí el problema fundamental es asociar 


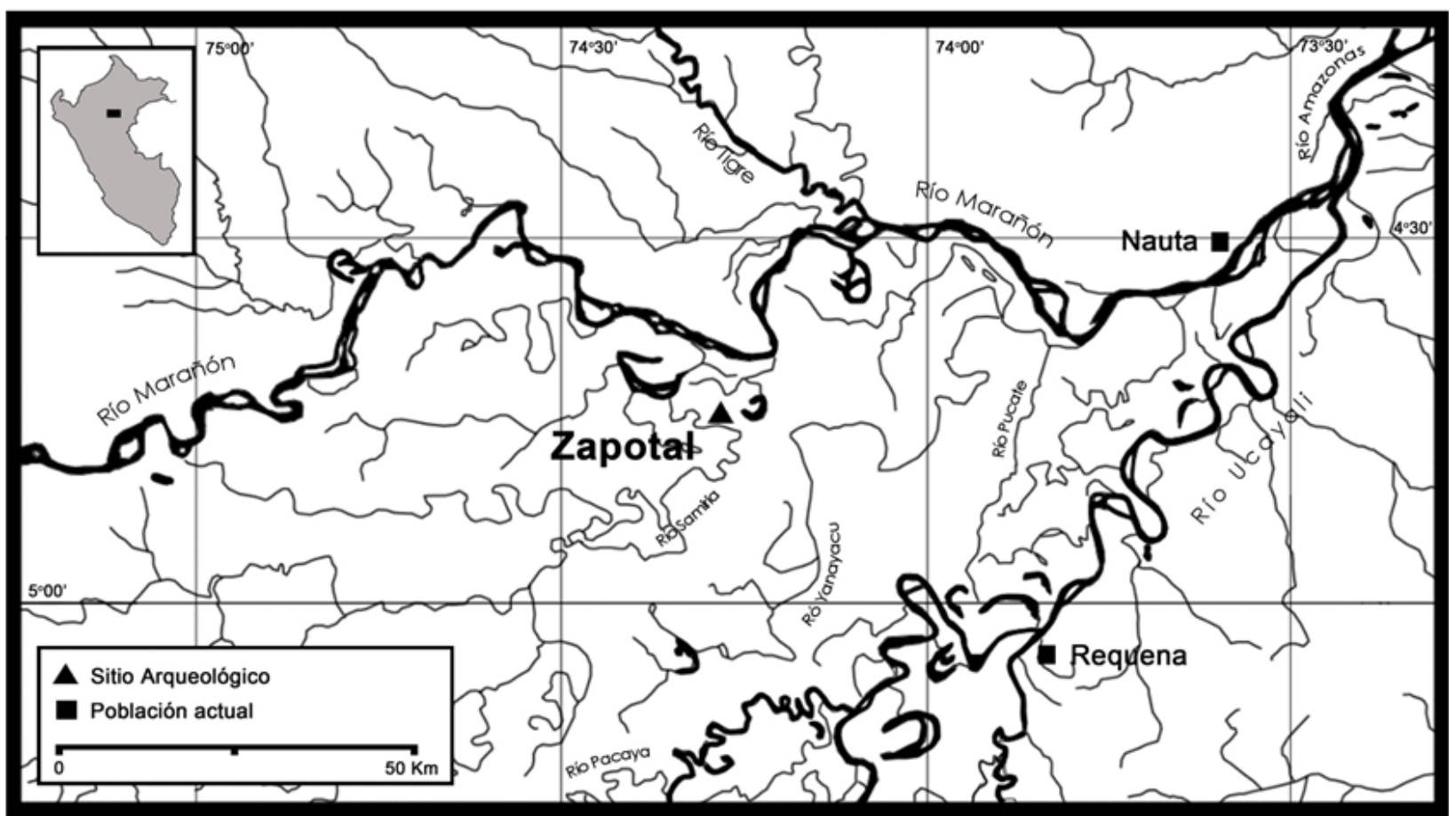

Fig. 8. Mapa de la confluencia de los ríos Marañón y Ucayali donde se ubica el sitio arqueológico de El Zapotal y la Reserva Nacional del Pacaya-Samiria.

lengua y cultura, el cual no siempre puede ser válido, mencionamos el caso Yanesha, vecinos y contemporáneos de los Shipibo-Conibo, comparten el mismo estilo en su cerámica, pero los Yanesha hablan el Arawac; así mismo se trató de definir el problema de donde vinieron en base a deducciones lógicas sin mayor soporte de material arqueológico.

\section{Nuestros aportes arqueológicos}

A partir del 2001, iniciamos nuestras investigaciones en la Reserva Nacional del Pacaya-Samiria, realizamos excavaciones en el sitio «El Zapotal» a pocos kilómetros del poblado actual de San José del Samiria, cercana a la confluencia del Marañón y Ucayali donde se forma el Amazonas, (Fig. 8), hemos publicado varios artículos en los años 2002a, 2002b, 2008 y 2011.

Nuestra hipótesis antes de iniciar las excavaciones arqueológicas en el sitio de El Zapotal, por su ubicación geográfica en la cuenca del río Samiria cerca a la confluencia de los ríos Marañón y Ucayali y las referencias etnohistóricas, suponíamos que el sitio de El Zapotal probablemente pertenecía a una de las antiguas y grandes poblaciones vistas por los españoles en 1542 a los cuales llamaron Omagua hoy Cocamas, el cual en la actualidad ocupan la zona de estudio, entre los ríos Marañón y Ucayali por tal razón teníamos también dentro de nuestros objetivos definir la extensión o tamaño del asentamiento de El Zapotal (Morales 2002).

En la primera campaña del 2001, se cumplió este objetivo en base a una metodología de trabajo que consistió en excavaciones de pequeñas cuadrículas de $1 \times 1$ metro de lado a lo largo del bosque cercano a la laguna Yarina donde se encuentra el sitio y de esta manera se pudo determinar la extensión de 510 metros de largo por un promedio de 170 metros de ancho; este método además nos permitió definir por lo menos dos sectores claramente notorios, la zona de cementerio y la zona de viviendas; sobre esta base al año siguiente trabajamos dos objetivos, excavaciones en área en la zona de cementerio y cuadriculas mucho más amplias de $3 \times 2$ metros en el área de viviendas domésticas.

El material cultural de las excavaciones estuvo orientado al análisis de los estilos de cerámica con el propósito de determinar su cronología relativa e identificar la cultura a la que pertenece, en base al análisis tipológico y estilístico de sus atributos. 


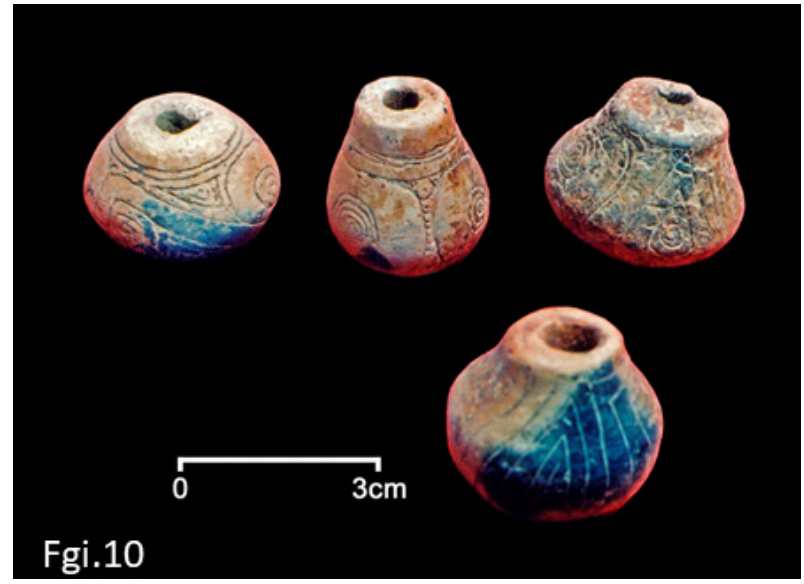

Fig. 10. Ruecas o piruros de cerámica de las excavaciones de El Zapotal, con diseños incisos similares al estilo Cumancaya.

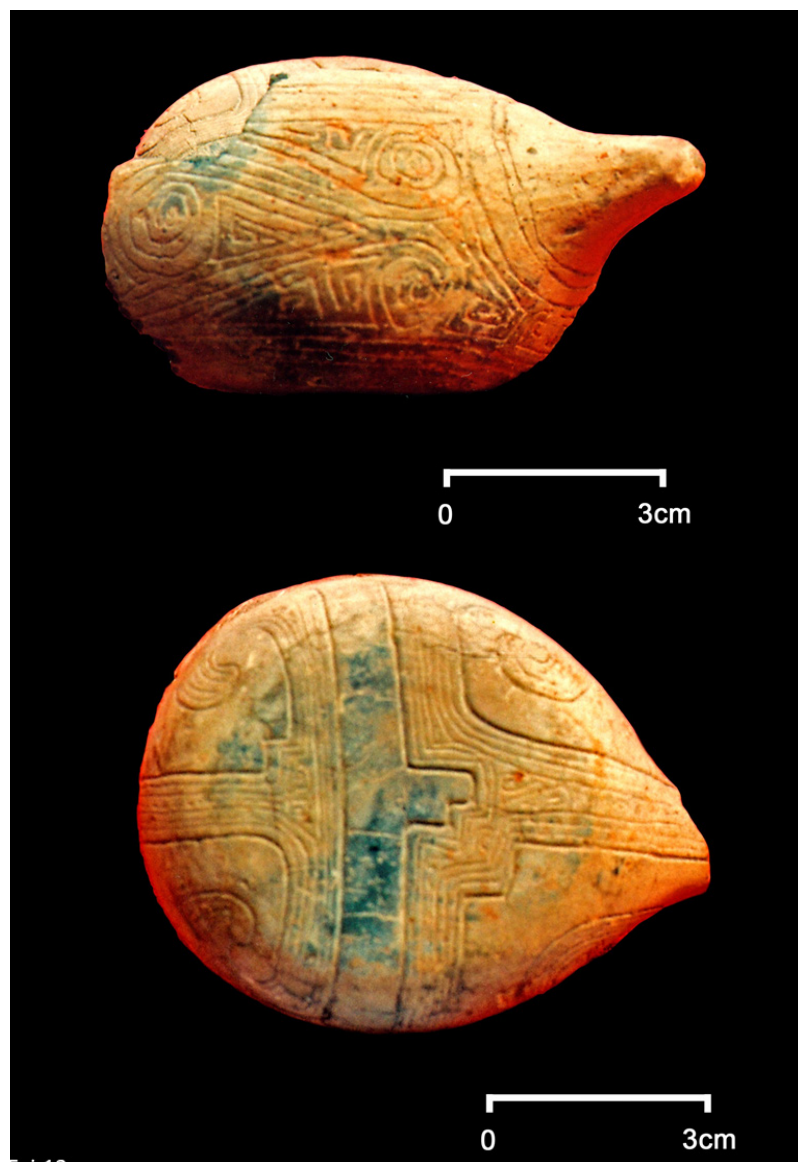

Fig. 11 y 12. Cuencos pequeños con diseños incisos de líneas gruesas y finas de El Zapotal.

En un segundo momento el 2002, surgió la necesidad de entender la presencia de ciertos artefactos vinculados a contextos funerarios, para lo cual tuvimos que realizar trabajos etnográficos en la comunidad Shipibo-Conibo y en base a la llamada

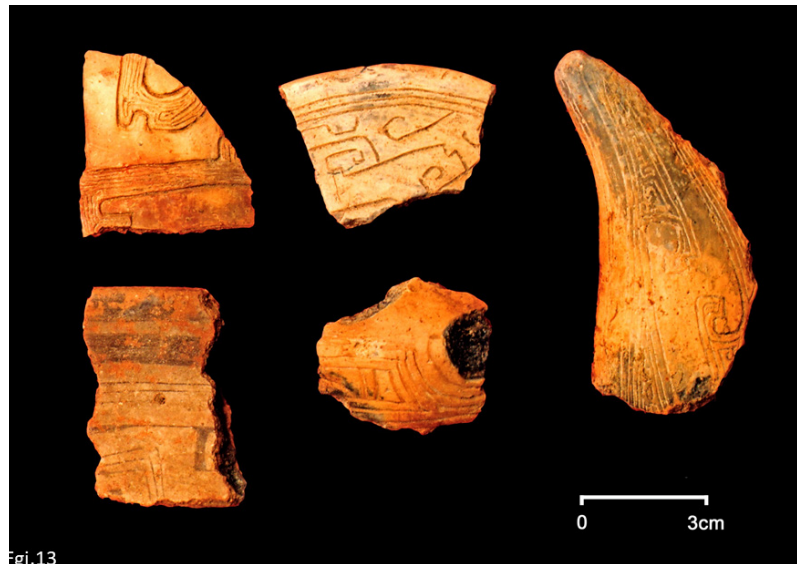

Fig. 13. Diseños incisos en líneas gruesas y finas y también pintadas con líneas negras sobre fondo blanco, en fragmentos de cerámica del sitio de El Zapotal.

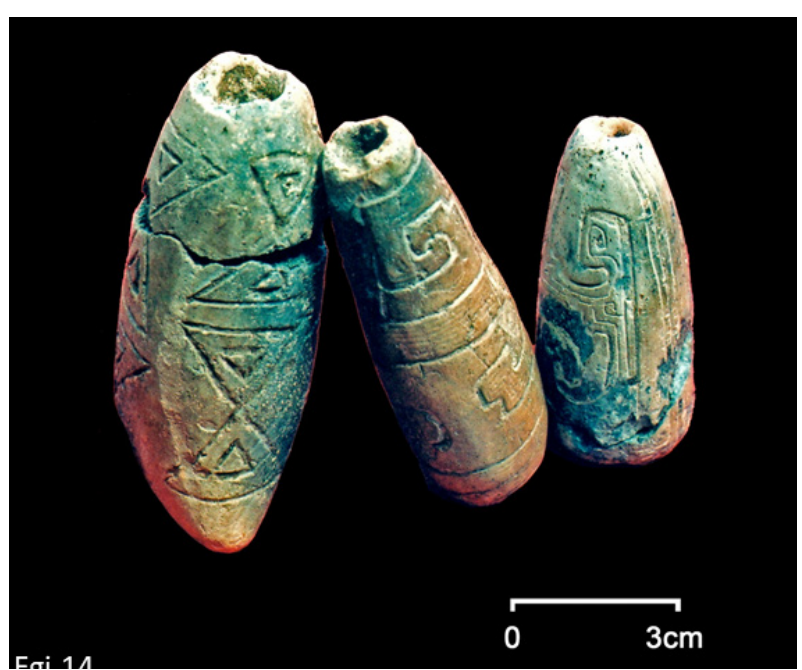

Fig. 14. Artefactos «Shibinantes» usados en ritos de Circuncisión de la mujer con diseños incisos anchas y finas, estilo pre-ShipiboConibo inciso de El Zapotal.

Etno-arqueología definida de manera particular por nosotros como Arqueología Viva (Morales 2008), tratar de entender algunos aspectos socioculturales de estos artefactos.

El 2003 el análisis final de la cerámica, nos permitió afirmar que en el sitio de El Zapotal existió un complejo alfarero el cual puede ser separado en tres estilos bastante conocidos para la Amazonía: la primera es la cerámica inciso con diseños geométricos, triángulos y espirales (Fig. 10), se vincula al estilo Cumancaya del Ucayali Central. Un segundo estilo es la cerámica pintada de estilo policromo rojo, blanco y negro vinculada a la Amazonía Central (Fig. 15), ambas con una diferenciación temporal a nivel estratigráfico. 


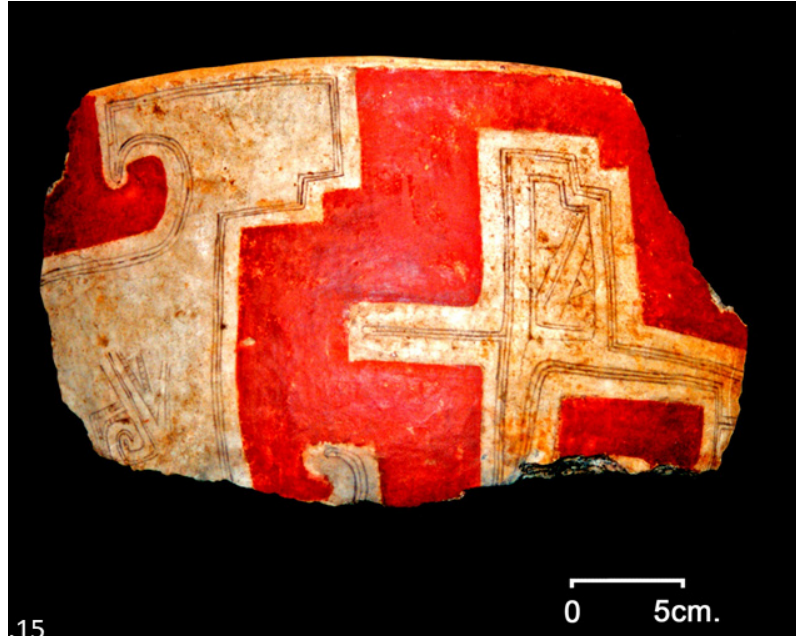

Fig. 15. Fragmento Policromo rojo-blanco y líneas finas de color negro del estilo el Pre Shipibo-Conibo Pintado.

Un segundo grupo de cerámica inciso, es algo particular al anterior, se trata de objetos ceremoniales, pequeños cuencos finamente pulidos sobre cuya base hay diseños geométricos trazados con líneas anchas y líneas muy finas (Fig.11, 12 y 13), esto mismo ocurre en artefactos pequeños que simulan penes, «Shibinantis» (Fig. 14)

El tercer estilo es el policromo que usa la pintura blanca, roja y negra, entre ellas destaca un gran fragmento con diseños geométricos trazados en franjas anchas en rojo y blanco y sobre las franjas blancas se trazan líneas muy finas de color negro las que forman triángulos y espirales (Fig.15), para nosotros este es un elemento clave porque creemos encontrar aquí los antecedentes de los estilos Cocama y Shipibo pintado, por combinar líneas anchas y líneas finas, tradición que ocurre en el estilo policromo de Amazonía Central; un segundo fragmento también clave es un plato de fondo negro sobre la cual con líneas blancas se logran diseños estilizados de cabezas de serpiente cósmica, (Fig.16), en este caso el estilo se parece más a la fase Caimito del Ucayali , con el diseño de la llamada «serpiente cósmica» de Shipibos y Cocamas.

En base a los tres estilos de cerámica propusimos la existencia de dos complejos estilos a los cuales culturalmente los denominamos: A). El estilo pre Cocama-Shipibo-Conibo pintado y B) El estilo pre Shipibo-Conibo inciso, este último con dos componentes el similar al estilo Cumancaya y el Inciso de líneas muy finas en objetos ceremoniales (Morales 2002).

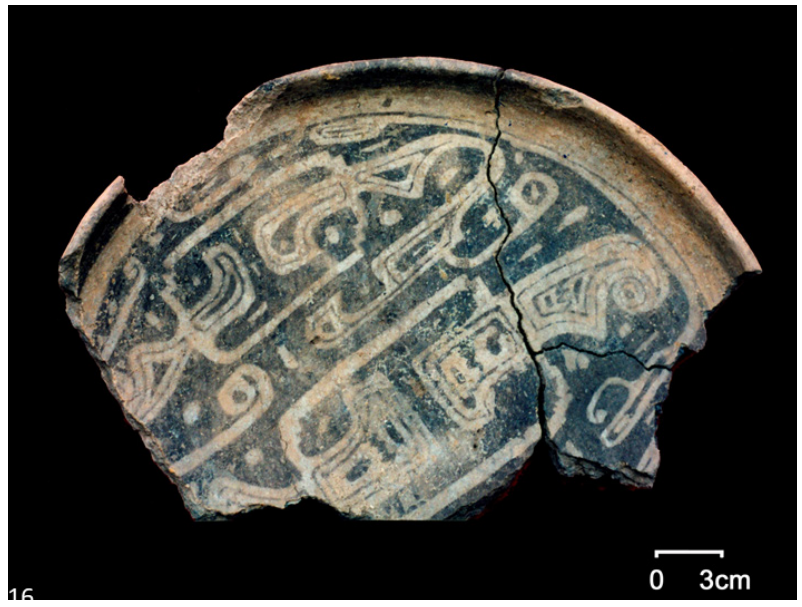

Fig. 16. Plato con diseños de la serpiente cósmica estilizada, es llamada «Roni» por los Shipibos, encontrada en excavaciones en El Zapotal.

Pero lo más importante de nuestros hallazgos arqueológicos en el sitio del Zapotal que nos acercaban a los Shipibo-Conibo fueron los entierros secundarios en ollas de cerámica con un engobe rojo y sus contextos asociados, en el cual se encontró cráneos de frente achatada, más los artefactos que simulaba penes fueron reconocidos por los propios Shipibos como «Shibinantes», usados en los ritos de pubertad. Sobre la base del cráneo de frente achatada, los Shibinantes y la forma de entierros secundarios, desarrollamos mediante la etno arqueología o memoria viva de los actuales nativos, tres conceptos socioculturales que identifican plenamente a la cultura Shipibo-Conibo: el concepto de identidad en base a los cráneos de frente achatada, el concepto de la muerte, en base a los entierros secundarios en urnas de cerámica y el concepto de honor en el rito de pubertad en base a los Shibinantes (Morales 2008). Este comportamiento social identifica plenamente a los Panos, ShipiboConibo más que a Tupi-Warani o Cocamas en el sitio El Zapotal.

También para nosotros, en lo que se refiere a estilos de cerámica, está bien definido señalar que el actual estilo polícromo de los Shipibo-Conibo tiene sus antecedentes en el estilo policromo de El Zapotal y en el estilo pre Shipibo-Conibo inciso y ambas a la vez estarían vinculadas a la tradición Policroma del Napo, Miracangeras, Marajo y Caimito, lo que si no podemos afirmar con certeza es que esta tradición estilística esté vinculada a los Pano hablantes, más bien lo que se podría deducir es que los Panos de la tra- 
dición Cumancaya, estaban aprendiendo en el sitio El Zapotal el estilo Policromo de Amazonía Central.

\section{Problemas de cronologia, ¿cuándo ocurrieron los hechos?}

La cronología relativa en base a comparaciones estilísticas de la cerámica del sitio de El Zapotal puede establecerse en base a las dos manifestaciones estilísticas: una primera vinculada a la cerámica inciso con figuras geométricas que forman triángulos escalonados y espirales a las cuales hemos identificado como de filiación Cumancaya y el segundo que hemos llamado el estilo pre Cocama-Shipibo-Conibo pintado y el estilo pre Shipibo-Conibo inciso que serían de la filiación del gran estilo Policromo que se acerca más al estilo Napo, Miracangeras, Marajoara y Caymito.

En referencias a la cronología absoluta en base a fechados de carbono 14, Donald Lathrap, plantea que el estilo Cumancaya empieza 810 d.C. en el Ucayali Central; otros fechados para el estilo Cumancaya fueron propuestos por DeBoer, Peter Roe y Scott Raymond (1975), en base a sus investigaciones en el alto Ucayali, afirmando que la tradición Cumancaya está presente en el Alto Ucayali desde los 810 a 1600 d. C., y al norte del bajo Ucayali como es el caso del sitio de Valencia en el río Corrientes tributario del río Tigre, no tenemos una presencia bien definida del estilo Cumancaya.

En el sitio arqueológico de Valencia según Fung (1981), el estilo de cerámica se aproxima al estilo Napo el cual está fechado entre 1100 a 1400 d. C. según Evans y Meggers (1968), mientras que Caymito en el Ucayali se ubica entre 1300 y 1400 d. C., sin embargo Valencia tiene notables diferencias con Napo y Caymito, especialmente por los motivos antropomorfos modelados, aplicados o pintados e incisos en sus urnas funerarias, en Valencia hay una vaga referencia de una cara pintada que se parece a Napo; por todo esto Rosa Fung, sitúa a Valencia entre los siglos IX y XIV d. C.

Aunque los arqueólogos Myers, Roe y otros creen que los Pano hablantes llegaron al Ucayali 300 años d. C, y el lingüista M D'Ans, incluso tal vez antes 100 d. C, no es muy claro esto, ya que en este lapso hubieron en el Ucayali dos estilos diferentes Yarinacocha y Pacacocha, mientras que la propuesta de 800 años
d.C. para Lathrap, se asocia al estilo Cumancaya el cual tiene hasta tres componentes diferentes, de los cuales la cerámica inciso con figuras geométricas escalonadas y espirales es la más dominante y se mantuvo hasta $1600 \mathrm{~d}$. C. en el Ucayali y la cual heredarían los Shipibo-Conibo; sin embargo hemos aclarado que el verdadero estilo Shipibo-Conibo está más asociado al estilo Policromo que se inicia en el Sitio de El Zapotal entre los ańos 1350 a 1450 d. C. de acuerdo a cuatro fechados radio carbónicos obtenidos en este sitio y que fueron publicados (Morales 2008).

Resumiendo: De acuerdo a los datos arqueológicos, la cronología y el origen de los Shipibo-Conibo es bastante polémica, Donald Lathrap, Thomas Myers y otros proponen fechas distintas para la llegada de los Pano a la cuenca del Ucayali, a ello se añade los estudios lingüísticos de Marcel D’Ans, quien afirma que los Pano hablantes ya estaban en la cuenca del Ucayali hace 100 años d. C., esta aparente contradicción, creemos que se resolvería, cuando los arqueólogos hablan de estilos o tradiciones en donde la llamada tradición Cumancya, tendría como antecedentes los estilos Yarinacocha, Pacacocha, siendo el Cumancaya un conjunto multiétnico producto de contactos e influencias muy importantes que modificaron su estilo original; esta historia representa las etapas culturales por las que tuvo que pasar para finalmente ser el estilo Shipibo-Conibo, es por ello que nosotros creemos que el componente más importantes de este estilo es la Tradición Polícroma de Amazonía central aprendida en el sitio de El Zapotal entre los ańos 1350 a $1450 \mathrm{~d}$. C. Con ello queremos decir que al igual que el mito, los Shipibo-Conibo pasaron por varias etapas de inicio en su historia (por lo menos cuatro), las cuales pueden ser consideradas como los varios orígenes al igual que refiere el mito.

\section{Bibliografia}

Belaunde, Luisa Elvira (2009). «Kené: Arte Ciencia y Tradición en diseño». Ed. Instituto Nacional de Cultura.

Brochado J.P. (1984). «An ecological model of the pottery and agriculture ento Eastern South America»Unpublished Ph.D dissertation University of Illinois at Urban Champaign 1980. A expansao dos 
Tupi de Cerámica da tradicao policromica Amazonia. Dédalo Sao Paulo 27: 65-82.

Carvajal, Gaspar de (1942 [1542]). «Relación del Nuevo descubrimiento del famoso Rio Grande que descubrió por muy gran ventura el Capitán Francisco de Orellana». Transcripciones de Fernández de Oviedo y Dr. Toribio Medina y estudio crítico del descubrimiento. Ed. Bibloteca Amazónica, Vol I, Quito-Ecuador.

Evans, Clifford and Meggers, Betty (1968). Archaeological investigation and the Rio Napo, Easteren Ecuador, Smithsonian Contributions at Anthropology, Vol.6, Washington D.C.

Fung Pineda, Rosa (1981). Notas y comentarios sobre el sitio de Valencia en el Río Corrientes. En Amazonia Peruana IV (7), 99-138.

Girald, Rafael (1958). Indios selváticos de la Amazonia peruana. Editores Libro Max.

Heath, Carolyn (2002a). «El Tiempo nos venció: Mitos y leyendas del grupo Shipibo-Conibo». En Una ventana hacia el infinito: arte shipibo-conibo. Ed. ICPNA- Miraflores.

Heath, Carolyn (2002b). Reproduciendo el cielo sobre la tierra: textiles y Alfarería del grupo Shipibo-Conibo. En Una ventana hacia el infinito, arte Shipibo-Conibo. Ed. ICPNA- Miraflores.

Lathrap, Donald (1970). «The Upper Amazon». Ancient Peoples and Placer General Editor Gleyn Daniel. 256 pp.

Marcal D’Ans, Andre (1973). «Reclasificación de la lengua Pano y datos Glotocronológicos para la etnohistoria de la Amazonía Peruana». En Revista del Museo Nacional $\mathrm{N}^{\circ}$ XXXIX. Lima-Perú.

Morales Chocano, Daniel (2002a). "Los ancestros del grupo cultural Shipibo-Conibo del Ucayali Central en la Amazonia Peruana» En Una ventana hacia el infinito. Arte Shipibo-Conibo. Ed. ICPNA-Miraflores.
Morales Chocano, Daniel (2002b). "Contactos entre Cocamas y Shipibos: Un acercamiento arqueológico en la Amazonía Peruana». En Investigaciones Sociales. Revista del IIHS-UNMSM. Año VI. N 10, pp. 47-70. Lima, Perú.

Morales Chocano, Daniel (2008). «Reconstruyendo algunos aspectos socioculturales de artefactos excavados en el Bajo Ucayali-Perú. En Amazonía Peruana, Arqueología, Centro Amazónico de Antropología y Aplicación Práctica- CAAAP. Tomo XV, N³1, pp211-249.

Morales Chocano, Daniel (2011). «La arqueología en la Amazonia peruana y sus relaciones con el área andina» En Por donde hay soplo. Actas y memoires29. Eds. Jean-Pierre Chaumeil, Oscar Espinosa de Rivero y Manuel Cornejo Chaparro.

Mujica, Ana (2002). "Los tejidos Shipibo-Conibo» En Una ventana hacia el infinito: Arte Shipibo-Conibo. Ed ICPNA-Miraflores.

Myers, Thomas (1970). «La tradición Cerámica Pacacocha del Alto Ucayali y sus relaciones. Tesis para el grado de $\mathrm{Ph}$. Univesity of Nebraska.

Myers, Thomas (2002). «Pacacocha y Cumancaya, dos tradiciones cerámicas en el Yarinacocha» University of Nebraska.

Porras, Pedro I (1987). «Investigaciones en las faldas del Sangay- Quito». En Artes gráficas Señal Impersonal CIA, Litd.

Raymond Scott J., DeBoer R. Roe Peter C. (1975). "Cumancaya: a peruvian ceramic tradition». Ocacional papers $N^{\circ} 2$ Departament of Archaeology the University of Calgary.

Rostain Stéphen (1997). «Arqueología del río Upana, Amazonía Ecuatoriana». Catálogo publicado bajo los auspicios del Banco central del Ecuador, ELF Hydrocarburos Equateur, Ecuadecor, Air France. 